\title{
Sulfur Management of NOx Adsorber Technology for Diesel Light-duty Vehicle and Truck Applications
}

Howard L. Fang, Jerry C. Wang and Robert C. Yu

Cummins Inc.

C. Z. Wan

Engelhard Corporation

Ken Howden

Department of Energy, Office of Advance Automotive Technologies

Reprinted From: Emissions: Advanced Catalyst and Substrates, Measurement and Testing, and Diesel Gaseous Emissions

(SP-1801)

Powertrain \& Fluid Systems

Conference \& Exhibition 
All rights reserved. No part of this publication may be reproduced, stored in a retrieval system, or transmitted, in any form or by any means, electronic, mechanical, photocopying, recording, or otherwise, without the prior written permission of SAE.

For permission and licensing requests contact:

SAE Permissions
400 Commonwealth Drive
Warrendale, PA 15096-0001-USA
Email: permissions @ sae.org
Fax: $\quad 724-772-4891$
Tel: $\quad 724-772-4028$

Tel: $\quad 724-772-4028$

For multiple print copies contact:

SAE Customer Service

Tel: $\quad$ 877-606-7323 (inside USA and Canada)

Tel: $\quad$ 724-776-4970 (outside USA)

Fax: $\quad$ 724-776-1615

Email: CustomerService@sae.org

\section{ISBN 0-7680-1319-4}

\section{Copyright $\odot 2003$ SAE International}

Positions and opinions advanced in this paper are those of the author(s) and not necessarily those of SAE. The author is solely responsible for the content of the paper. A process is available by which discussions will be printed with the paper if it is published in SAE Transactions.

Persons wishing to submit papers to be considered for presentation or publication by SAE should send the manuscript or a 300 word abstract of a proposed manuscript to: Secretary, Engineering Meetings Board, SAE.

\section{Printed in USA}




\title{
Sulfur Management of NOx Adsorber Technology for Diesel Light-duty Vehicle and Truck Applications
}

\author{
Howard L. Fang, Jerry C. Wang and Robert C. Yu \\ Cummins Inc. \\ C. Z. Wan \\ Engelhard Corporation \\ Ken Howden \\ Department of Energy, Office of Advance Automotive Technologies
}

Copyright (C) 2003 SAE International

\begin{abstract}
Sulfur poisoning from engine fuel and lube is one of the most recognizable degradation mechanisms of a $\mathrm{NO}_{\mathrm{x}}$ adsorber catalyst system for diesel emission reduction. Even with the availability of 15 ppm sulfur diesel fuel, $\mathrm{NO}_{x}$ adsorber will be deactivated without an effective sulfur management. Two general pathways are currently being explored for sulfur management: (1) the use of a disposable $\mathrm{SO}_{\mathrm{x}}$ trap that can be replaced or rejuvenated offline periodically, and (2) the use of diesel fuel injection in the exhaust and high temperature de-sulfation approach to remove the sulfur poisons to recover the $\mathrm{NO}_{\mathrm{x}}$ trapping efficiency. The major concern of the de-sulfation process is the many prolonged high temperature rich cycles that catalyst will encounter during its useful life. It is shown that $\mathrm{NO}_{\mathrm{x}}$ adsorber catalyst suffers some loss of its trapping capacity upon high temperature lean-rich exposure. With the use of a disposable $\mathrm{SO}_{\mathrm{x}}$ trap to remove large portion of the sulfur poisons from the exhaust, the $\mathrm{NO}_{\mathrm{x}}$ adsorber catalyst can be protected and the numbers of de-sulfation events can be greatly reduced.
\end{abstract}

Spectroscopic techniques, such as DRIFTS and Raman, have been used to monitor the underlying chemical reactions during $\mathrm{NO}_{\mathrm{x}}$ trapping/ regeneration and de-sulfation periods, and provide a fundamental understanding of $\mathrm{NO}_{x}$ storage capacity and catalyst degradation mechanism using model catalysts. This paper examines the sulfur effect on two model $\mathrm{NO}_{\mathrm{x}}$ adsorber catalysts. The chemistry of $\mathrm{SO}_{\mathrm{x}}$ /base metal oxides and the sulfation product pathways and their corresponding spectroscopic data are discussed.

\section{INTRODUCTION}

$\mathrm{NO}_{\mathrm{x}}$ adsorber technology relies on a storagereduction approach that involves removal of $\mathrm{NO}_{\mathrm{x}}$ from the exhaust under lean conditions by adsorption, followed by periodic regeneration of the adsorbent along with reduction of the released $\mathrm{NO}_{\mathrm{x}}$ under rich conditions (1-9). The operational temperature range of the $\mathrm{NO}_{\mathrm{x}}$ adsorber catalyst is governed by the low and high limits. The low limit is controlled by the light-off temperature required for the catalysts to oxidize $\mathrm{NO}$ into $\mathrm{NO}_{2}$ and the upper limit is determined by the temperature of thermodynamic stability of the trapped $\mathrm{NO}_{\mathrm{x}}$ species (e.g. nitrates of barium or alkali metals). The adsorbent function is extremely susceptible to deactivation from sulfur oxides in the exhaust by the formation of sulfated species that hinder adsorption sites available for $\mathrm{NO}_{\mathrm{x}}$ storage. $\mathrm{SO}_{\mathrm{x}}$ competes for the same active sites for $\mathrm{NO}_{\mathrm{x}}$ adsorption to form thermodynamically more stable sulfate species. The sites covered by these sulfated species are difficult to regenerate at normal operation temperatures (e.g. $<500^{\circ} \mathrm{C}$ ). Even with the availability of $15 \mathrm{ppm}$ sulfur diesel 
fuel, $\mathrm{NO}_{\mathrm{x}}$ adsorber will be totally deactivated within a fraction of the useful life if there is no effective sulfur management in place.

There are two general approaches to sulfur management. The first is to use a disposable $\mathrm{SO}_{\mathrm{x}}$ trap that can be replaced or rejuvenated offline periodically. The trapping capacity and the thermal stability of the trapped sulfur are the two critical issues for $\mathrm{SO}_{\mathrm{x}}$ trap development. The second is the use of diesel fuel injection in the exhaust and high temperature de-sulfation strategy to remove the sulfates in an attempt to recover the $\mathrm{NO}_{\mathrm{x}}$ trapping efficiency. The combination of the two approaches provides a robust strategy in tackling sulfur

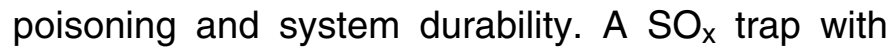
high capacity can reduce the number of desulfation events, thus, the fuel penalty and prolong the useful life of the $\mathrm{NO}_{\mathrm{x}}$ adsorber.

In addition to fuel sulfur, lube sulfur also plays a role in sulfur loading and performance degradation in $\mathrm{NO}_{x}$ adsorber. These include sulfurs derived from ZDDP's, the sulfurized detergents and Scontaining antioxidants. It is also expected that phosphorus and ash contents from oil additives may induce certain masking and alloying effects to the catalysts. Although a development of the future emission friendly oil compatible with aftertreatment systems (such as the category of PC-10) is underway, contribution from the oil sulfur needs to be considered to the exhaust system.

To estimate the total sulfur flux and phosphorus flux the catalyst system will encounter in useful life of 150,000 miles, an average fuel economy of 20 mpg (for a vehicle of GVWR between 5000 and $8500 \mathrm{lbs}$ ) and a $\mathrm{NO}_{\mathrm{x}}$ adsorber catalyst volume of 11.6 liter are used in the calculation. Fuel sulfur will contribute about 235 grams of sulfur based on 10 ppm (average) sulfur fuel and oil sulfur (average $0.2 \%$ [S] and $0.12 \%$ [P]) will add about 45 grams of sulfur and 28 grams of phosphorus to the engine exhaust. It is determined that the $\mathrm{NO}_{\mathrm{x}}$ adsorber will be totally deactivated in less than 25,000 miles of operation if there is no sulfur management strategy in place. Without a $\mathrm{SO}_{\mathrm{x}}$ trap, the $\mathrm{NO}_{\mathrm{x}}$ adsorber needs about 25 events of high temperature desulfation strategy on every $1 \mathrm{~g} \mathrm{~S} / \mathrm{L}$ accumulated sulfur flux. With a $\mathrm{SO}_{\mathrm{x}}$ trap, the $\mathrm{NO}_{\mathrm{x}}$ adsorber will significantly reduce the numbers of de-sulfation events depending upon the size of the $\mathrm{SO}_{\mathrm{x}}$ trap and a reasonable $\mathrm{SO}_{\mathrm{x}}$ trap replacement schedule.

\section{SULFUR TRAP DEVELOPMENT}

A $\mathrm{SO}_{\mathrm{x}}$ trap is designed to protect a $\mathrm{NO}_{\mathrm{x}}$ adsorber from sulfur poisoning. An ideal $\mathrm{SO}_{\mathrm{x}}$ trap shall capture all engine-out $\mathrm{SO}_{x}$ under engine operation conditions for the entire life of the exhaust aftertreatment system. The $\mathrm{NO}_{x}$ adsorber catalyst will then prolong its function without going into difficult deSO $\mathrm{S}_{\mathrm{x}}$ process to recover from deactivation due to the sulfur poisoning. However, such a system needs a $\mathrm{SO}_{\mathrm{x}}$ trap very large in volume that would make the system impractical. A realistic $\mathrm{SO}_{\mathrm{x}}$ trap will have a limited volume with a limited total capacity, thus, a limited useful life that is far less than the required life of the exhaust aftertreatment system. If the capacity of a $\mathrm{SO}_{\mathrm{x}}$ trap is sufficiently high and only a couple of replacements of the $\mathrm{SO}_{\mathrm{x}}$ trap in the useful life of an aftertreatment device is needed, the use of a $\mathrm{SO}_{\mathrm{x}}$ trap may become a competitive option in a $\mathrm{NO}_{x}$ adsorber technology system. In addtion, a sulfur trap can also act as a scavenger for oil derived poisons such as phosphorus and zinc compounds although the longterm impact of those poisons on $\mathrm{NO}_{x}$ adsorber catalyst performance is not well understood.

To demonstrate the feasibility of the $\mathrm{SO}_{\mathrm{x}}$ trap concept for light-duty truck (LDT) application, catalyst samples of a $\mathrm{SO}_{\mathrm{x}}$ trap material with various loadings of the trapping component were obtained from Engelhard Corporation. In a laboratory reactor, the $\mathrm{SO}_{\mathrm{x}}$ trap samples were exposed to various sulfur flux at $300^{\circ} \mathrm{C}$ in a simulated diesel exhaust. The aged $\mathrm{SO}_{x}$ trap samples were then analyzed for the sulfur content. The $\mathrm{SO}_{\mathrm{x}}$ trapping efficiency defined as the total sulfur collected on the $\mathrm{SO}_{\mathrm{x}}$ trap for a given accumulated sulfur flux to which the catalyst sample exposed is presented in Figure 1. The relative sulfur flux at unit one in the Figure is equivalent to a flux quantity of $15 \mathrm{~g}[\mathrm{~S}] / \mathrm{L}$ for a $\mathrm{SO}_{\mathrm{x}}$ trap with optimal loading. It can be seen that minimum amount of $\mathrm{SO}_{x}$ will breakthrough if $\mathrm{SO}_{x}$ trap is replaced frequently whenever sulfur flux reaches 0.5 relative quantity. Preferably, $\mathrm{SO}_{\mathrm{x}}$ trap may be replaced after it is exposed to a total flux of 1.5 times of the relative quantity to allow some sulfur breakthrough. In such case, the use of a $\mathrm{SO}_{\mathrm{x}}$ trap can remove $70 \%$ of the sulfur from the exhaust for a reasonable useful life. Thus, it reduces the number of de-sulfation events necessary to rejuvenate the downstream $\mathrm{NO}_{\mathrm{x}}$ adsorber when compared to a system without the presence of a $\mathrm{SO}_{\mathrm{x}}$ trap and that will prolong the life of the $\mathrm{NO}_{\mathrm{x}}$ adsorber. 
In an engine aging experiment, a $\mathrm{SO}_{\mathrm{x}}$ trap of 2.5 liters in volume was aged on a Cummins 5.9L Bengine for 240 hours to simulate 20,000 miles operation. The use of an undersize $\mathrm{SO}_{\mathrm{x}}$ trap with reduced component loading was to accelerate the $\mathrm{SO}_{\mathrm{x}}$ deposition and to investigate the trapping efficiency under high space velocity conditions. The aging cycle consisted of a combination of three steady state modes (i.e. A18, C25 and C75 defined in EPA supplemental test cycles) each for 20 minutes in the cycle and the aging cycle repeated every hour. The temperatures of the aging ranged from $215^{\circ} \mathrm{C}$ to $380^{\circ} \mathrm{C}$ and the space velocities varied from $65 \mathrm{~K}$ to $120 \mathrm{~K}$. Fuel sulfur and total fuel consumption were monitored during the entire aging. The total sulfur flux to the $\mathrm{SO}_{\mathrm{x}}$ trap was estimated to be equivalent to 1.25 times the relative flux defined in Figure 1. After the aging, the $\mathrm{SO}_{x}$ trap was analyzed for its sulfur content. It was determined that $80 \%$ of the sulfur from engine-out was collected by the $\mathrm{SO}_{\mathrm{x}}$ trap. As shown in the Figure 1, the result of the engine-aged $\mathrm{SO}_{\mathrm{x}}$ trap follows closely with the laboratory data and that validates the $\mathrm{SO}_{\mathrm{x}}$ trap concept.

\section{SOx Trapping Effciency}

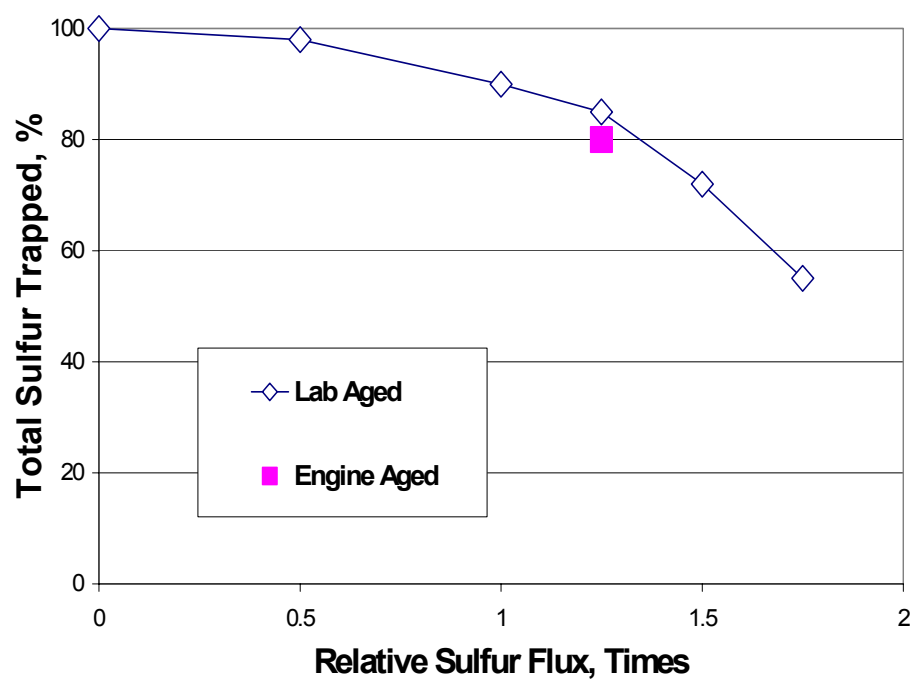

Figure 1: $\mathrm{SO}_{\mathrm{x}}$ trapping efficiency as a function of accumulated sulfur flux.

\section{SPECTROSCOPIC ANALYSES OF SULFATION AND DESULFATION OF MODEL NOx ADSORBER CATALYSTS}

\section{EXPERIMENTAL}

DRIFTS (diffused reflectance FTIR) and micro Raman techniques were used to characterize surface adsorbed species. The experimental setups for both units have been described before (1). All DRIFTS spectra were taken with $2 \mathrm{~cm}^{-1}$ resolution and a MCT detector. The IR data were normalized against a $\mathrm{KBr}$ background. For surface IR measurement, a caution needs to be paid to the saturation of IR detector due to high diffuse signal. The common practice to minimize such saturation is to dilute the sample with $\mathrm{KBr}$ powder in a 1:1 weight ratio. All Raman spectra were collected using a Renishaw microRaman system equipped with holographic Notch filters, an $\mathrm{Ar}^{+}$laser, and a liquid- $\mathrm{N}_{2}$ cooled CCD detector (10-12). All data analysis was done using standard curve deconvolution algorithm within GRAMS32.

Two model catalysts, alumina-based $\mathrm{BaO} / \mathrm{Pt} / \mathrm{Al}_{2} \mathrm{O}_{3}$ and titania-based alkali metal carbonate/ $\mathrm{Pt} / \mathrm{TiO}_{2}$. were compared. Both samples were firstly treated by exposing to $\mathrm{H}_{2}$ gas $\left(4 \%\right.$ in $\mathrm{N}_{2}$ ) at $250^{\circ} \mathrm{C}$ for $1 \mathrm{hr}$ in an attempt to remove some unwanted surface adsorbing species. On sulfation, the catalyst powder was loaded in a packed-bed reactor and exposed to $992 \mathrm{ppm} \mathrm{SO}_{2}$ in air with a flow rate of $30 \mathrm{ml} / \mathrm{min}$ at the desired temperatures. To simulate the de-sulfation event, the sulfated samples were exposed to $\mathrm{H}_{2}\left(4 \%\right.$ in $\left.\mathrm{N}_{2}\right)$ at the desired temperatures for various length of time duration. It is known that $\mathrm{H}_{2}$ and $\mathrm{CO}$ are more effective reductants than hydrocarbons. After each reaction, sample was rapidly cooled down to room temperature for spectroscopic analysis.

\section{RESULTS AND DISCUSSIONS}

Most commercial $\mathrm{NO}_{\mathrm{x}}$ adsorbers contain alkali or alkali earth metal oxides (under atmospheric condition surface species are most in carbonates or hydroxides) on $\mathrm{Pt} / \mathrm{Al}_{2} \mathrm{O}_{3}$ or $\mathrm{Pt} / \mathrm{TiO}_{2}$ and subsequently supported onto monolithic structure. We have been applying spectroscopic techniques to identify and quantify surface adsorbing/ desorbing species responsible for sulfation and desulfation processes. The surface characterization provides insights about the underlying chemistry of the adsorption/desorption processes and the 
degradation mechanism (13-26). The temperature and temporal probes of surface adsorbing species permit us to derive thermodynamic and kinetic parameters required for model development (1318).

\section{Spectroscopy study on sulfation}

Disposable $\mathrm{SO}_{\mathrm{x}}$ adsorber is developed under a sacrificial strategy in an attempt to avoid or reduce the de-sulfation events. When base metal oxides are exposed to $\mathrm{SO}_{2}$, two types of products are generally generated, the bulk sulfate and various surface oxysulfur species. The trapping capacity depends on the product distribution between surface and bulk, which in turn is a strong function of surface basicity and temperature. Bulk sulfates are more likely formed on samples with low surface area while more surface oxy-sulfur species are expected for samples with high surface area (16-18). High temperature will favor the formation of sulfates and pyro-sulfates. The bulk sulfate is desirable because of its thermal stability.

The major trapping mechanisms of $\mathrm{NO}_{\mathrm{x}}$ and $\mathrm{SO}_{\mathrm{x}}$ are displacement reactions involving sorbate materials of base metal oxides or alkali metal carbonates. Both surface and bulk oxy-sulfur species are generated when catalysts are exposed to $\mathrm{SO}_{2}$ under appropriate conditions. The surface oxy-sulfur species are precursors for bulk sulfate formation. Based on structural rearrangement among $\mathrm{M}-\mathrm{O}$ bonds, particularly in the vicinity of $\mathrm{Pt}$, the adsorbed $\mathrm{SO}_{2}$ can couple with substrate oxygen or surface superoxides to form more stable surface sulfates. Surface $\mathrm{OH}$ groups may also play important roles in the formation of oxy-sulfur species through displacement or insertion reactions of $>\mathrm{OH}+\mathrm{SO}_{\mathrm{x}} \rightarrow>\mathrm{SO}_{\mathrm{x}} \mathrm{OH}$. The surface bisulfites can undergo further oxidation to form bisulfates and sulfates. Owing to its higher thermal stability, the formation of bi-sulfate is more favored than bi-sulfite. High temperature and low surface area will favor the formation of bulk sulfates and bisulfates. Upon long operation, bi-sulfates may combine to form pyro- or poly-sulfates with the reaction of $2 \mathrm{HSO}_{3}{ }^{-}$or $2 \mathrm{HSO}_{4}{ }^{-} \rightarrow \mathrm{S}_{2} \mathrm{O}_{5}{ }^{2}$ or $\mathrm{S}_{2} \mathrm{O}_{7}{ }^{-}+$ $\mathrm{H}_{2} \mathrm{O}$. Pyrosulfates are physically bulky and are believed to be the precursors for S-poisoning.

Under higher reaction temperatures $\left(>500^{\circ} \mathrm{C}\right)$, pyro-sulfates may decompose to form free sulfates. The bulk sulfate formation is controlled by an overall oxidation mechanism involving reactions of
$\mathrm{SO}_{2}+[\mathrm{O}]+\mathrm{MO} \rightarrow \mathrm{MSO}_{4}$ where $\mathrm{M}=\mathrm{Ba}^{++}, \mathrm{Ca}^{++}$, etc. The reaction rates depend on the ease of generating $\mathrm{SO}_{3}$ and the basicity of the metal center in controlling the reaction of $\mathrm{MO}+\mathrm{SO}_{3} \rightarrow \mathrm{MSO}_{4}$. Oxidizing reagents such as ceria and catalyzing components such as $\mathrm{Pt}$ are commonly used to speed up the reaction. Typical reactions are $\mathrm{SO}_{2}+$ $2 \mathrm{CeO}_{2} \rightarrow \mathrm{SO}_{3}+\mathrm{Ce}_{2} \mathrm{O}_{3}$ and $\mathrm{SO}_{2}+[\mathrm{O}]($ Pt-site $) \rightarrow$ $\mathrm{SO}_{3}$. It is expected that bulk species are more difficult to reduce than the surface species, possibly due to the more ionic nature of the bulk sulfated species.

For more neutral metal oxides such as $\mathrm{Al}_{2} \mathrm{O}_{3}$ and $\mathrm{TiO}_{2}$, surface adsorbed $\mathrm{SO}_{2}$, or in general the $\mathrm{SO}_{\mathrm{x}}$ $(x=2-4)$, are the main species. This is in contrast to the base metal oxides where the formation of metal sulfates is the main pathway. The surface adsorbed $\mathrm{SO}_{2}$ can be identified through its rotational contour. The transition frequency of Q-branch of vapor-like $\mathrm{SO}_{2}$, normally located at $1358 \mathrm{~cm}^{-1}$, is so distinct that it can be unequivocally identified on various substrates. We have established a database regarding the sulfation on various metal oxides, such as $\mathrm{BaO}, \mathrm{CaO}, \mathrm{NiO}, \mathrm{Al}_{2} \mathrm{O}_{3}$ and $\mathrm{TiO}_{2}$, etc. The IR spectra of $\mathrm{Al}_{2} \mathrm{O}_{3}$ and $\mathrm{TiO}_{2}$ after exposing to $\mathrm{SO}_{2}$ in air (at $250^{\circ} \mathrm{C}$ for $1 / 2 \mathrm{hr}$ ) are compared. The major buildups are located at $1358 / 1180 \mathrm{~cm}^{-1}$ for $\mathrm{Al}_{2} \mathrm{O}_{3}$ and $1369 / 1180 \mathrm{~cm}^{-1}$ for $\mathrm{TiO}_{2}$. The 1358 or 1369 $\mathrm{cm}^{-1}$ band carrying certain rotation contour with the Q-branch characteristic suggests the surface adsorbed $\mathrm{SO}_{2}$. The sulfate formation can be quantified through the buildup of the $1180 \mathrm{~cm}^{-1}$ band. The intensity of the sulfate band at $1180 \mathrm{~cm}^{-}$ 1 is stronger in $\mathrm{Al}_{2} \mathrm{O}_{3}$ than that in $\mathrm{TiO}_{2}$. This is expected because $\mathrm{TiO}_{2}$ is less basic in nature than $\mathrm{Al}_{2} \mathrm{O}_{3}$. The trapping capacities of neutral metal oxides are much less than the base metal oxides such as $\mathrm{BaO}$ or $\mathrm{CaO}$.

Figure 2 shows the IR spectra of the $\mathrm{BaO} / \mathrm{Pt} / \mathrm{Al}_{2} \mathrm{O}_{3}$ powder sulfated at various temperatures for $1 / 4 \mathrm{hr}$. Major spectral changes consist of (1) buildups of the sulfated species on Ba-sites (including 1186 $\mathrm{cm}^{-1}$ for bi-sulfates, $1085 \mathrm{~cm}^{-1}$ for sulfates and 980 $\mathrm{cm}^{-1}$ for sulfites); (2) buildups of the sulfated species on Al-sites (1360 $\mathrm{cm}^{-1}$ for sulfates); and (3) the features of the $\mathrm{OH}$ loss including $\mathrm{OH}$ stretchings $\left(3000-3600 \mathrm{~cm}^{-1}\right)$ and $\mathrm{OH}$-bendings $\left(1630 \mathrm{~cm}^{-1}\right)$. The $1186 \mathrm{~cm}^{-1}$ band can also be assigned as the tri-dentate sulfate where the three S-O bonds are attached to surface (vs. the 1085 
$\mathrm{cm}^{-1}$ band of bi-dentate sulfate with two S-O bonds attached to the surface). The sulfite band at 980 $\mathrm{cm}^{-1}$ diminishes at higher temperature, $\left(\mathrm{T}>400^{\circ} \mathrm{C}\right)$. Sulfites can be easily oxidized to more stable sulfates.

The quantification of sulfated species can be normalized against the internal bands of $\mathrm{Al}_{2} \mathrm{O}_{3}$. Typical spectral features of $\mathrm{Al}_{2} \mathrm{O}_{3}$ are 2060 and $2340 \mathrm{~cm}^{-1}$. For $\mathrm{T}<350^{\circ} \mathrm{C}$, sharp bands at 1620 and $1760 \mathrm{~cm}^{-1}$ can also be used. The linear dependence of In(sulfate buildup) vs. $1 / \mathrm{T}\left({ }^{\circ} \mathrm{K}\right)$ is also shown in Figure 2 where the slope, equivalent to $-\Delta \mathrm{E}_{\mathrm{a}} / \mathrm{R}$, should reflect the activation energy through the Arrhenius equation. The $\Delta \mathrm{E}_{\mathrm{a}}$ for bisulfate formation is found to be lower than the value observed for sulfate, 4.3 vs. $6 \mathrm{kcal} / \mathrm{mole}$. Both are kinetically favored reactions.

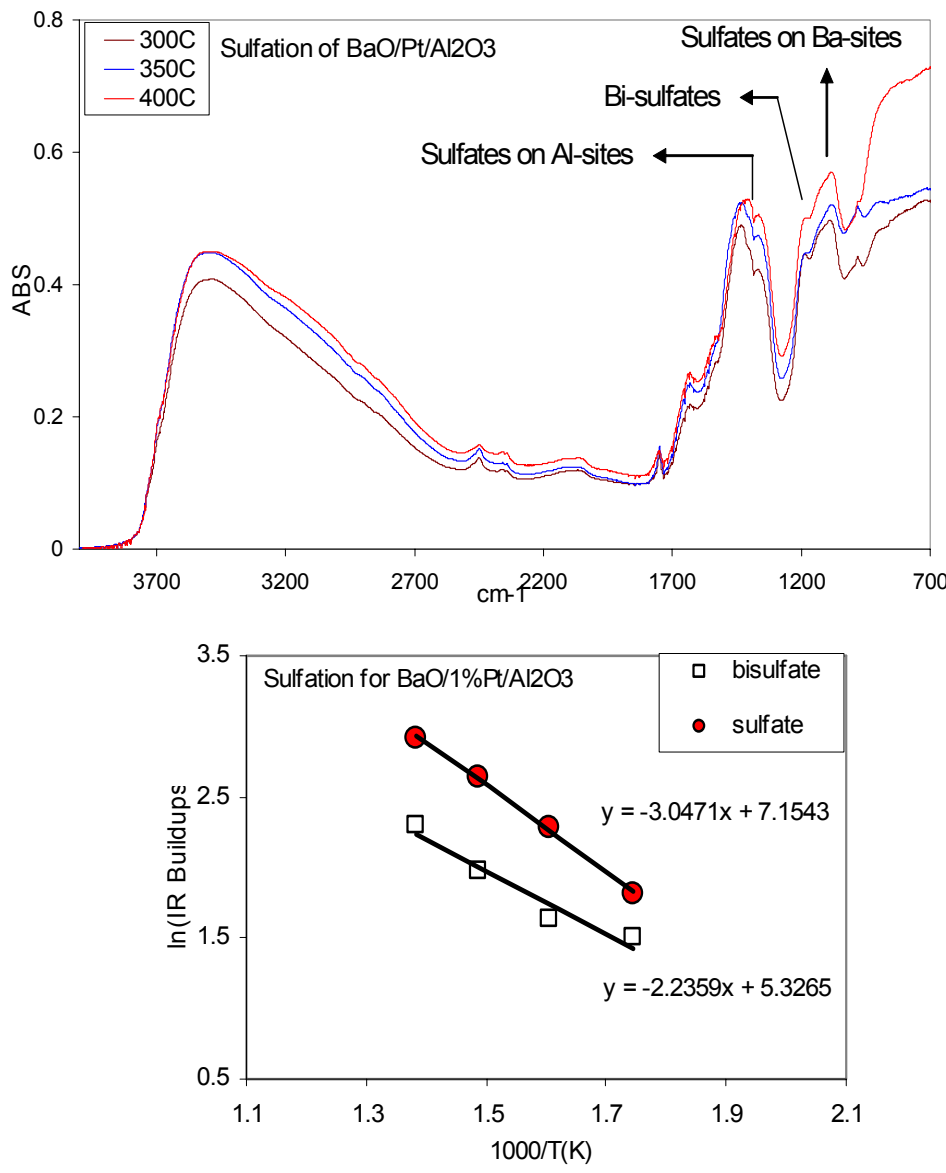

Figure 2: Sulfation of model $\mathrm{BaO} / 1 \% \mathrm{Pt} / \mathrm{Al}_{2} \mathrm{O}_{3}$ at various temperatures measured by DRIFTS.

Buildups of surface sulfated species must be proportional to the remaining active sites on the surface. Following the Elovich adsorption mechanism (19), the surface buildup of certain species $q$ at a time $t$ would follow an equation of $\mathrm{dq} / \mathrm{dt}=\mathrm{kexp}(-\beta \mathrm{q})$ where $\mathrm{k}$ is the reaction rate and $\beta$ is a constant which is independent of pressure and temperature. With an integration of $\exp (\beta q) d q=$ $\bullet k d t$, we can easily derive a relationship of $q \sim \ln (\mathrm{t})$. If $\mathrm{q}$ is plotted as a function of $\ln (\mathrm{t})$, a linear curve should be obtained. Figure 3 shows the Elovich plot for sulfate and bi-sulfate formation on Ba-sites.
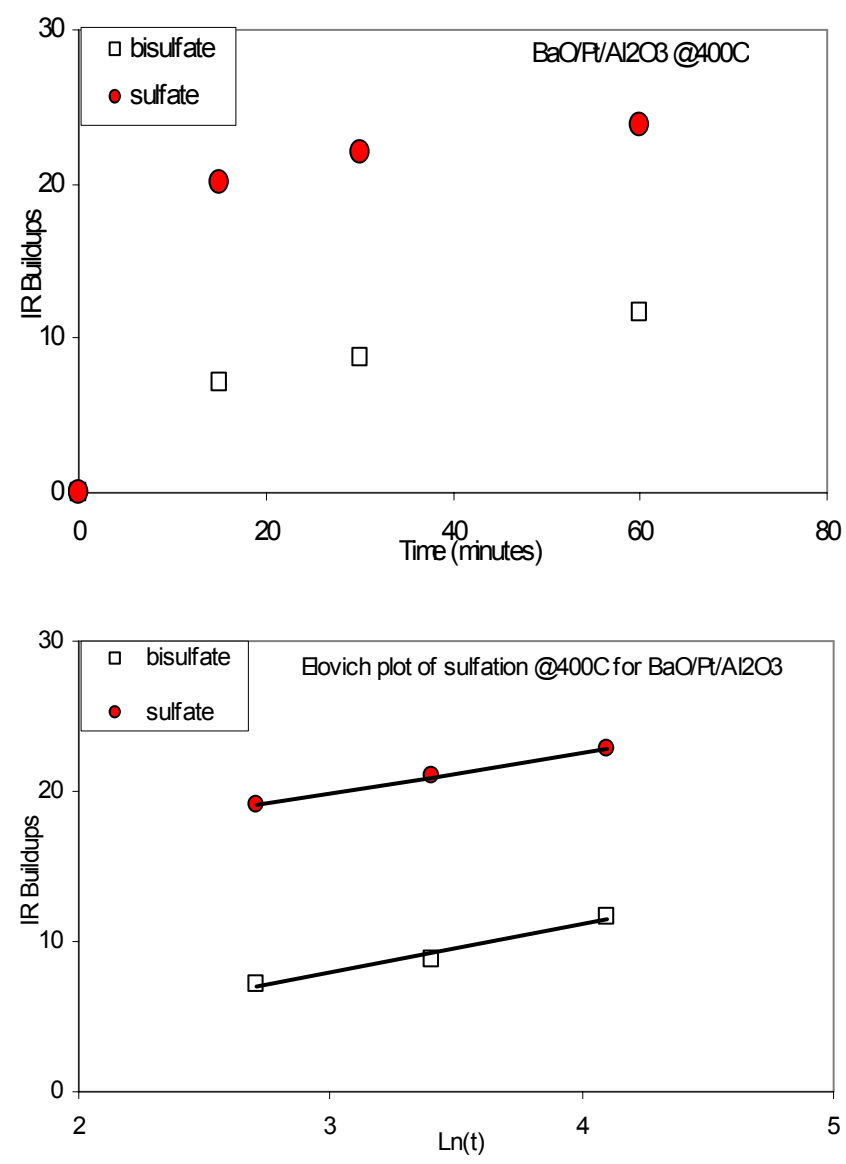

Figure 3: Sulfation kinetics and the corresponding Elovich plot measured by DRIFTS

Figure 4 shows the differential IR spectra of the sample of alkali metal carbonate $/ \mathrm{Pt} / \mathrm{TiO}_{2}$ during sulfation at various temperatures for $1 / 4 \mathrm{hr}$. Major spectral changes consist of: (1) the depletion of metal carbonate around $1500 \mathrm{~cm}^{-1}$; (2) buildups of the sulfated species including sulfite at $980 \mathrm{~cm}^{-1}$, sulfate at $1080 / 1190 \mathrm{~cm}^{-1}$ and bi-sulfate at 1260 $\mathrm{cm}^{-1}$; and (3) a slight $\mathrm{OH}$ growth in the $\mathrm{OH}$ stretchings around $3500 \mathrm{~cm}^{-1}$. The linear dependence of the plot of $\ln$ (sulfate loss) vs. $1 / T(K)$ with the slope of $-\Delta E_{a} / R$ is also shown in Figure 4. The $\Delta \mathrm{E}_{\mathrm{a}}$ is found $\sim 7.6 \mathrm{kcal} / \mathrm{mole}$ which is essentially similar to the value observed for 
Barium-based catalyst. The spectral change in the $\mathrm{OH}$-stretching region for the titania-system is substantially lower than the one observed for the Barium-system.
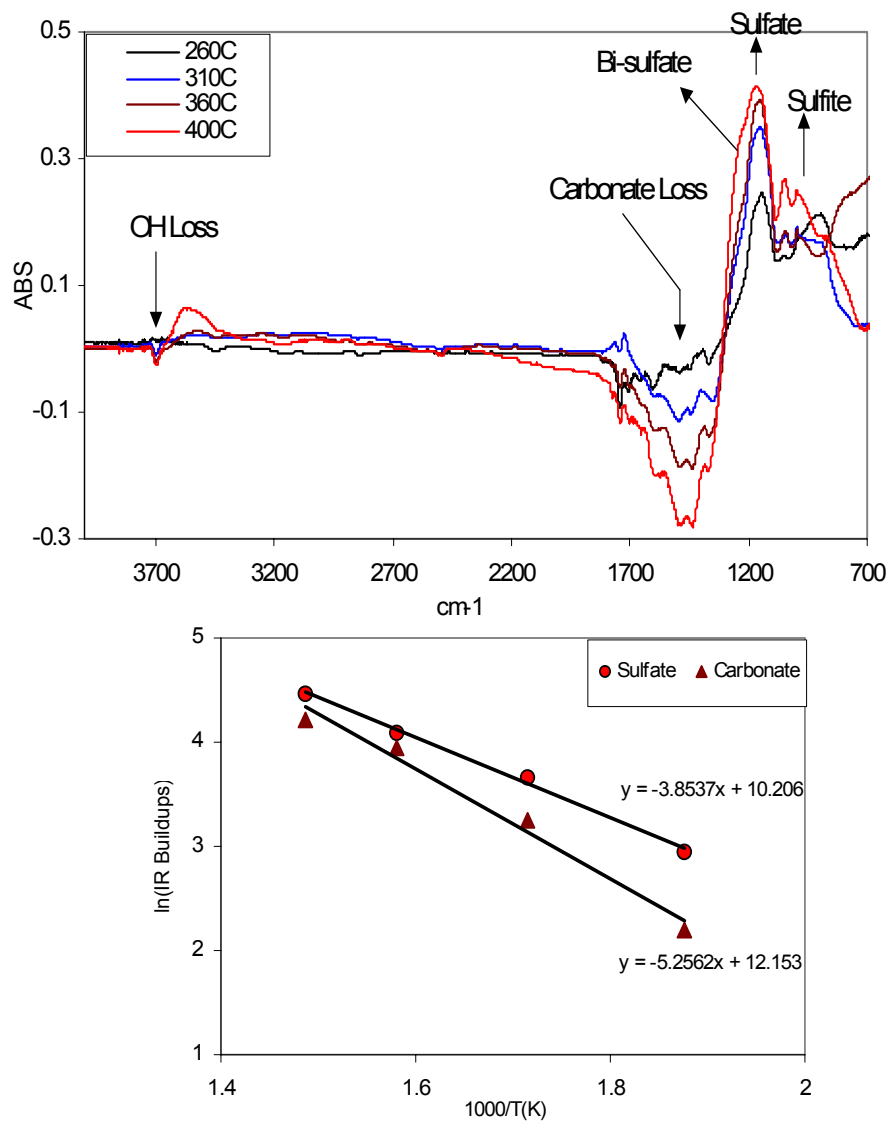

Figure 4: Differential IR of sulfation, the fresh sample spectrum is subtracted from the spectrum of the sulfated sample, on model titania-system.

Figure 5 shows the Raman spectra of the sulfation of $\mathrm{BaO} / \mathrm{Pt} / \mathrm{Al}_{2} \mathrm{O}_{3}$ system at various temperatures. In the spectral range of $500-1200 \mathrm{~cm}^{-1}$, three features can be seen. They are carbonate at $1053 \mathrm{~cm}^{-1}$, sulfate stretching at $980 \mathrm{~cm}^{-1}$ and sulfate bending at $610 \mathrm{~cm}^{-1}$. Since the decomposition of carbonate is not significant during the temperature window, the sulfate bands can be normalized against the strength of the carbonate. The Arrhenius plot is also shown in Figure 5. The $\Delta \mathrm{E}_{\mathrm{a}}$ is found $\sim 5$ $\mathrm{kcal} / \mathrm{mole}$, which is in good agreement with the DRIFTS data.

The Raman data for the sulfation on the model titania-system is shown in Figure 6. The intensity of the sulfate band at $990 \mathrm{~cm}^{-1}$ increases with temperature and its strength can be normalized against the $1635 \mathrm{~cm}^{-1} \mathrm{TiO}_{2}$ band. The $\Delta \mathrm{E}_{\mathrm{a}}$ derived from the slope of the Arrhenius plot is found 7.5 $\mathrm{kcal} /$ mole which is also in excellent agreement with the DRIFTS data. Kinetically, sulfation for the titania-system seems to be identical to the Bariumsystem.

\section{Spectroscopic study on de-sulfation}

As described in the previous section, sulfation is a kinetically favored reaction, with fairly low activation energy. Under the reduction condition, the sulfated species need to be reduced to sulfur species with lower oxidation states, where $\mathrm{SO}_{2}$ and $\mathrm{H}_{2} \mathrm{~S}$ are expected to be the major products. During desulfation, it is desirable to have the less strongly bound surface $\mathrm{SO}_{2}$ species since they are much easier to remove than the sulfate. However, sulfate species populate in a sulfated NOx adsorber sample. Applying spectroscopic techniques, attempt was made to quantify the surface change during the de-sulfation process for model catalysts using $\mathrm{H}_{2}$ $\left(4 \%\right.$ in $\left.\mathrm{N}_{2}\right)$ as the reductant. For sulfated model samples of $\mathrm{Pt} / \mathrm{Al}_{2} \mathrm{O}_{3}$ and $\mathrm{Pt} / \mathrm{TiO}_{2}$, the most possible chemistry relies on the reactions of $2 \mathrm{HSO}_{4}^{-}+5 \mathrm{H}_{2}$ $\rightarrow \mathrm{S}^{=}+\mathrm{SO}_{2}+6 \mathrm{H}_{2} \mathrm{O}$, and $2 \mathrm{SO}_{4}{ }^{=}+4 \mathrm{H}_{2} \rightarrow \mathrm{S}^{=}+$ $4 \mathrm{H}_{2} \mathrm{O}$ and $\mathrm{SO}_{4}{ }^{=}+\mathrm{H}_{2} \rightarrow \mathrm{SO}_{2}+2 \mathrm{OH}^{-}$.

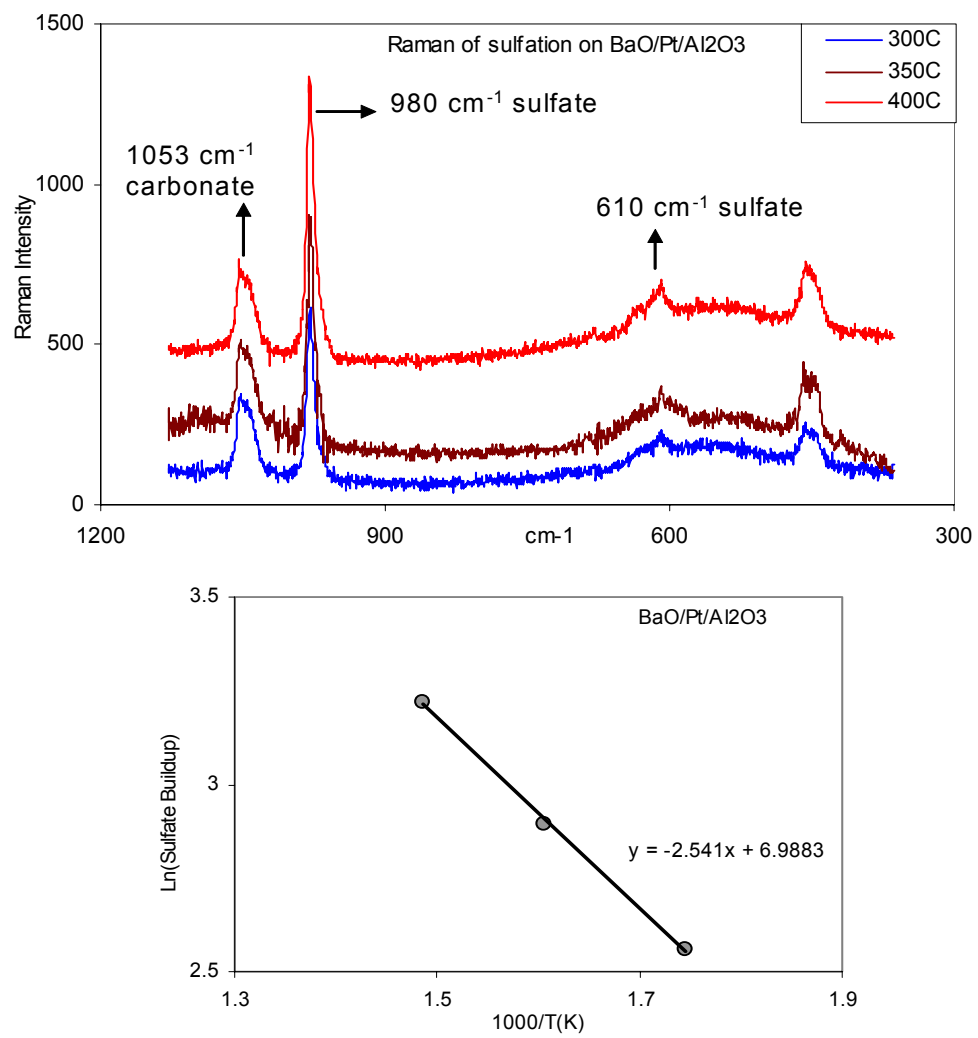

Figure 5: Sulfation on $\mathrm{BaO} / \mathrm{Pt} / \mathrm{Al}_{2} \mathrm{O}_{3}$ at various temperatures measured by microRaman. 
The IR spectra of the $\mathrm{BaO} / \mathrm{Pt} / \mathrm{Al}_{2} \mathrm{O}_{3}$ system during de-sulfation at various temperatures are shown in Figure 7. Sample was firstly sulfated at $400^{\circ} \mathrm{C}$ by exposing to $\mathrm{SO}_{2}$ (992 ppm in air) for $1 \mathrm{hr}$. The sulfated sample was then put in a reactor and exposed to $\mathrm{H}_{2} \quad\left(4 \%\right.$ in $\left.\mathrm{N}_{2}\right)$ at the desired temperatures for $1 / 4 \mathrm{hr}$. As shown in Figure 7, major changes consist of: (1) the depletion of the sulfated species on Ba-sites at 1100 and $1186 \mathrm{~cm}^{-1}$; (2) the depletion of the sulfated species on Al-sites at 1350 $\mathrm{cm}^{-1}$; and (3) the features of the $\mathrm{OH}$ loss including $\mathrm{OH}$-stretchings around $3000-3600 \mathrm{~cm}^{-1}$ and $\mathrm{OH}-$ bendings at $1630 \mathrm{~cm}^{-1}$. The band intensity change of sulfates on Ba-sites is more significant than the one on Al-sites.

Since the integrated strength of the carbonate around 1350 and $1600 \mathrm{~cm}^{-1}$ does not change with the temperature, all absorbance changes of the sulfated species can be quantified by normalizing their absorption strength against the carbonate band. The significant loss of $\mathrm{OH}$ suggests a rearrangement of surface hydroxyl groups when adsorbed sulfate is under reduction. Figure 7 also shows the plot of sulfate buildup vs. $1 / \mathrm{T}\left({ }^{\circ} \mathrm{K}\right)$ and the $\Delta \mathrm{E}_{\mathrm{a}}$ for sulfate reduction is determined $17 \mathrm{kcal} / \mathrm{mole}$. Similar procedure was applied to the $1186 \mathrm{~cm}^{-1}$ band of bi-sulfate (or tri-dentate sulfate) and the $\Delta \mathrm{E}_{\mathrm{a}}$ for such reduction is determined $23 \mathrm{kcal} / \mathrm{mole}$. If the $1186 \mathrm{~cm}^{-1}$ band is assigned to sulfate, it is more difficult to reduce tri-dentate sulfates than normal sulfates.

The Raman spectra of the de-sulfation of $\mathrm{BaO} / \mathrm{Pt} / \mathrm{Al}_{2} \mathrm{O}_{3}$ system at various temperatures is shown in Figure 8. In the spectral region of $400 \sim 1200 \mathrm{~cm}^{-1}$, four features can be seen and three of them $\left(455,610\right.$ and $\left.980 \mathrm{~cm}^{-1}\right)$ can be attributed to sulfate formation. The $1053 \mathrm{~cm}^{-1}$ band can be assigned to carbonate of $\mathrm{BaCO}_{3}$ resulting as a reaction product of $\mathrm{BaO}$ with $\mathrm{CO}_{2}$ and moisture. The Raman band ratio between the sulfate and the carbonate can be used to quantify the de-sulfation process. Since the thermal decomposition of carbonate normally requires high temperatures and the carbonate loss during the current temperature window is insignificant, the sulfate loss can be normalized against the strength of the carbonate band. A typical Arrhenius plot is also shown in Figure 8. The $\Delta \mathrm{E}_{\mathrm{a}}$ is found $17 \mathrm{kcal} / \mathrm{mole}$, which is in excellent agreement with the DRIFTS data.
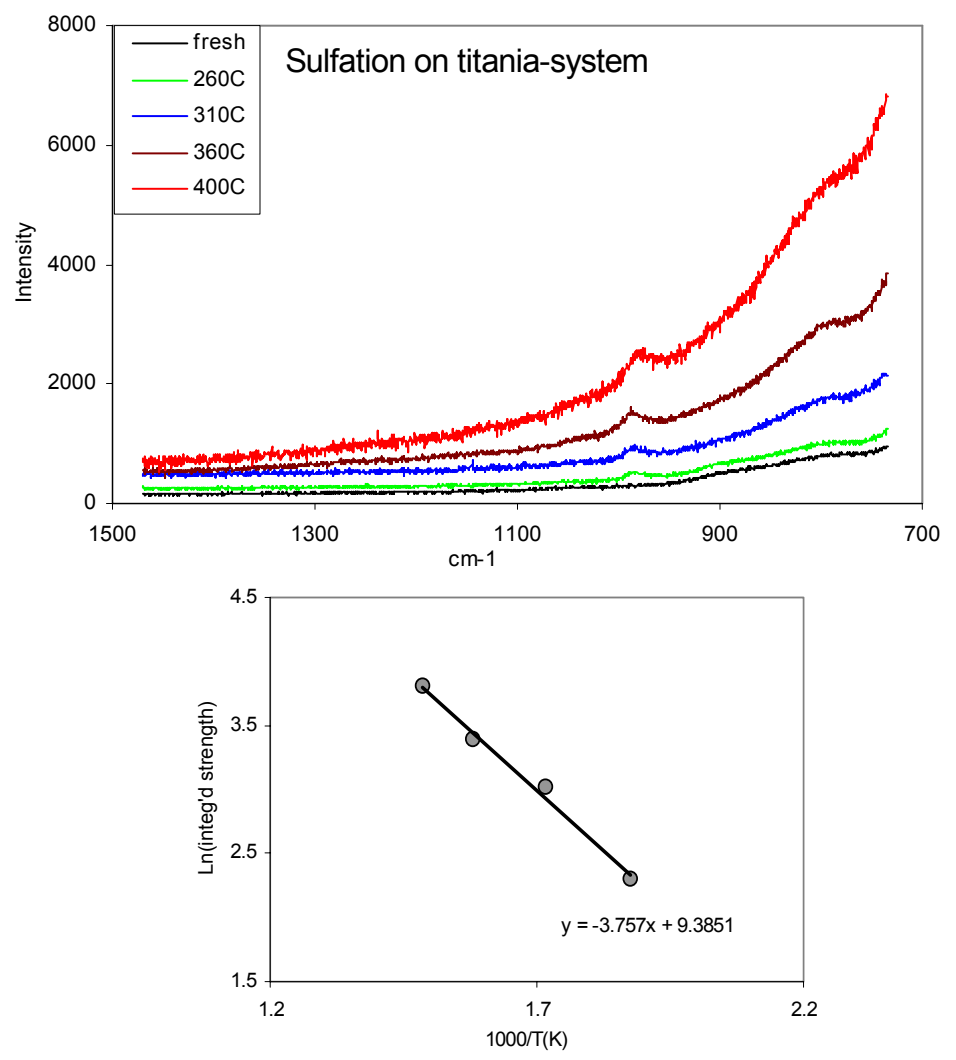

Figure 6: Sulfation on the model titania-system at various temperatures measured by microRaman
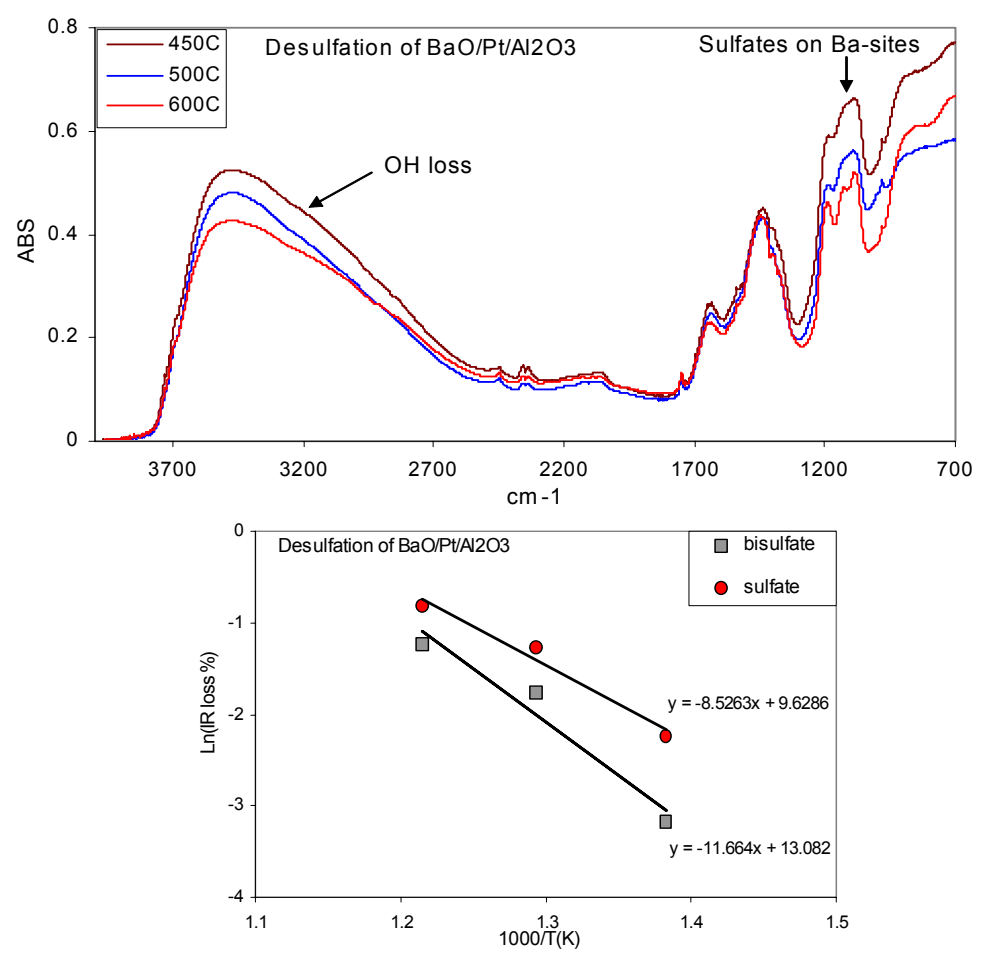

Figure 7: De-sulfation of model $\mathrm{BaO} / \mathrm{Pt} / \mathrm{Al}_{2} \mathrm{O}_{3}$ using $\mathrm{H}_{2}$ measured by DRIFTS. 
For the titania-system, the IR spectra during the desulfation at various temperatures are shown in Figure 9. Major spectral changes consist of: (1) the depletion of sulfites at $900 \mathrm{~cm}^{-1}$; (2) the depletion of sulfates at $1180 \mathrm{~cm}^{-1}$; and (3) the features of the $\mathrm{OH}$ loss including $\mathrm{OH}$-stretchings around $3000-3600 \mathrm{~cm}^{-}$ 1 and $\mathrm{OH}$-bendings at $1630 \mathrm{~cm}^{-1}$. The integrated strength of the carbonate bands around 1350 and $1600 \mathrm{~cm}^{-1}$ does not change with the temperature which can be used as reference to quantify the sulfated species. After normalization, a plot of In(sulfate loss) vs. $1 / T(K)$ gives a straight line with a slope of $-\Delta \mathrm{E}_{a} / \mathrm{R}$. This Arrhenius dependence is also shown in Figure 9 where the $\Delta \mathrm{E}_{\mathrm{a}}$ is found $\sim 11$ $\mathrm{kcal} / \mathrm{mole}$. The difference of $\sim 6 \mathrm{kcal} /$ mole in $\Delta \mathrm{E}_{\mathrm{a}}$ can account for the slightly lower temperature, $575^{\circ} \mathrm{C}$ vs. $650^{\circ} \mathrm{C}$, for de-sulfation between the two adsorber systems.

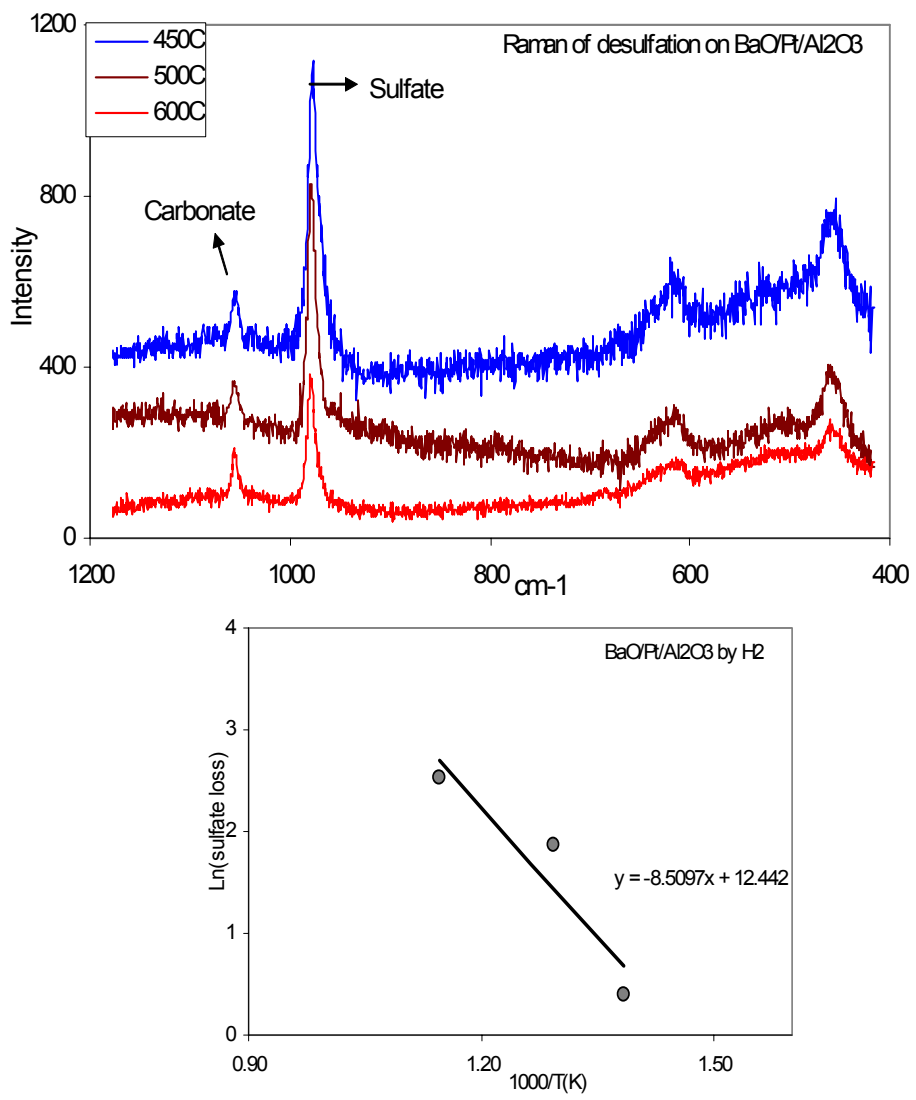

Figure 8: De-sulfation on model $\mathrm{BaO} / \mathrm{Pt} / \mathrm{Al}_{2} \mathrm{O}_{3}$ at various temperatures measured by microRaman

The Raman spectra of de-sulfation for $\mathrm{Pt} / \mathrm{TiO}{ }_{2}$ system at various temperatures is shown in Figure 10. With a continuous purge of $\mathrm{H}_{2}$, the intensity of the sulfate band at $990 \mathrm{~cm}^{-1}$ decreases with temperature indicating the reduction of sulfates. At $575^{\circ} \mathrm{C}$, most of the sulfates have reduced, but the buildups around $800 \sim 900 \mathrm{~cm}^{-1}$ still remain in the spectrum.

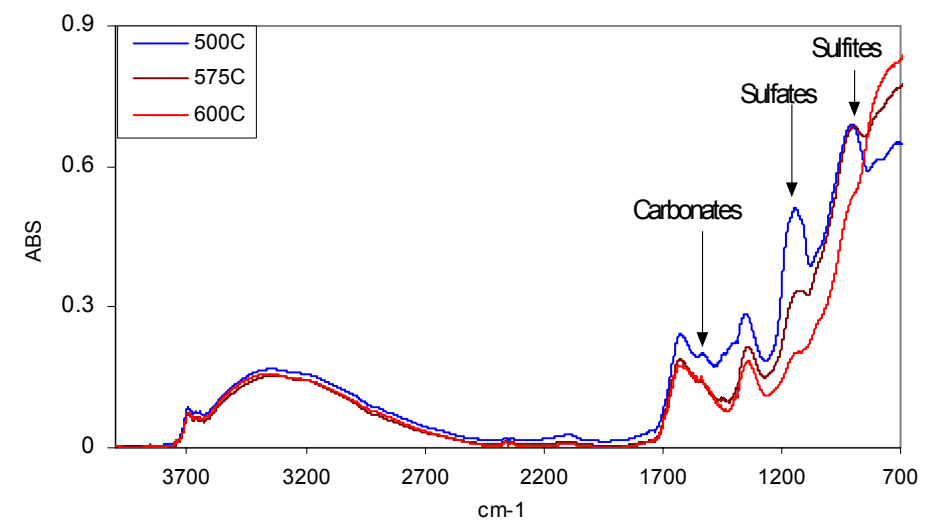

Figure 9: Temperature dependence of de-sulfation on the model titania-system.

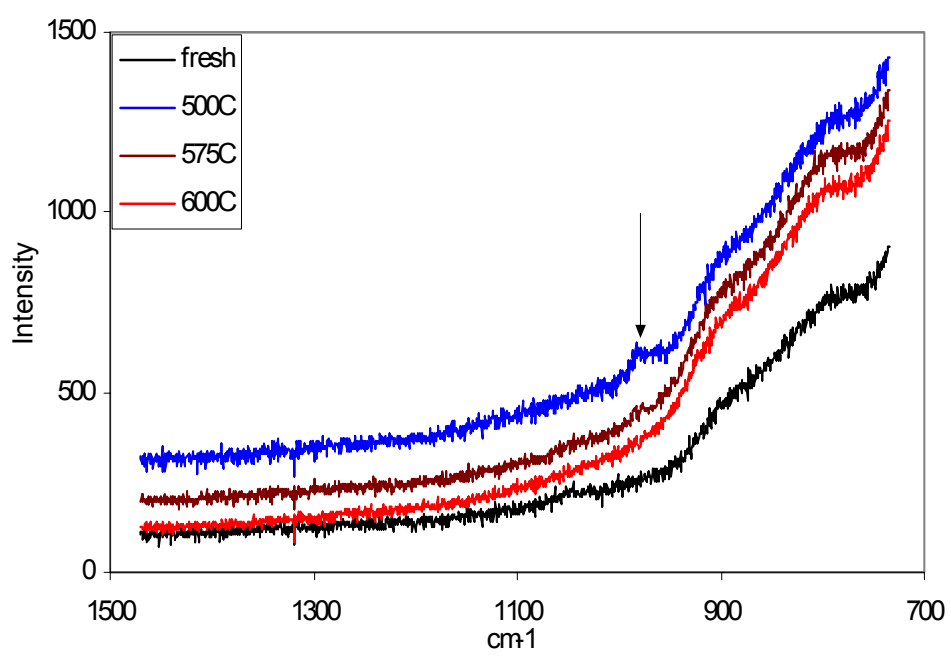

Figure 10: De-sulfation of the model titania-system (using $\mathrm{H}_{2}$ ) measured by microRaman. 
IR was also used to characterize one commercial $\mathrm{SO}_{\mathrm{x}}$ trap material. A fixed amount of the $\mathrm{SO}_{\mathrm{x}}$ absorber material was packed within a flow reactor and exposed to $\mathrm{SO}_{2}$ under the air at various temperatures. The flow rate of $\mathrm{SO}_{2} /$ air is $1000 \mathrm{sccm}$ and the corresponding space velocity is about 5000 $\left(\mathrm{min}^{-1}\right)$. The temperature range is from room temperature to $340^{\circ} \mathrm{C}$. The $\mathrm{SO}_{2}$ slip was evaluated with a $\mathrm{SO}_{\mathrm{x}}$ analyzer placed downstream from the flow reactor. After the sulfation for $2 \mathrm{hrs}$, the sample was cooled down to room temperature for spectroscopic measurement. Spectral buildup and depletion were analyzed to give clues to reaction rate as well as mass transfer mechanism.

The absorption spectra of the sulfated samples at different reaction temperatures are shown in Figure 11. Both buildup and depletion are seen in the spectra. As shown in Figure 11, a pair of depletion bands is observed at $1530 / 1410 \mathrm{~cm}^{-1}$ which can be attributed to the loss of certain metal-oxide bonds. The broad buildup observed around $1200 \mathrm{~cm}^{-1}$ can be assigned to the formation of various sulfates and bi-sulfates, including both surface and bulk species. The temperature response of the sulfate buildup shows a V-shape dependence. For $\mathrm{T}<140^{\circ} \mathrm{C}$, the sulfate buildup decreases with the temperature (with negative slope), but increases with the temperature in the range of $\mathrm{T}>140^{\circ} \mathrm{C}$ (with positive slope). The slope difference can be attributed to two different mechanisms of sulfation. In $\mathrm{T}>140^{\circ} \mathrm{C}$, the sulfation simply follows a kinetics governed by $\mathrm{MO}+\mathrm{SO}_{2}$ $+[\mathrm{O}] \rightarrow \mathrm{MSO}_{4}$ which will be accelerated with temperature. At $\mathrm{T}<140^{\circ} \mathrm{C}$, surface adsorbed $\mathrm{SO}_{2}$ may be the dominant sulfated species where the surface accumulation is inversely proportional to the temperature increase. This is consistent with the results on model metal oxides where surface adsorbed $\mathrm{SO}_{2}$ can be observed around $1358 \mathrm{~cm}^{-1}$ for $\mathrm{BaO}, \mathrm{CaO}$ and $\mathrm{Al}_{2} \mathrm{O}_{3}$, particularly for $\mathrm{T}<200^{\circ} \mathrm{C}$.

\section{CONCLUSION}

(1) Both DRIFTS and Raman techniques are sensitive probes for elucidating underlying chemistry on model catalysts for $\mathrm{NO}_{x}$ adsorbers.

(2) Disposable $\mathrm{SO}_{x}$ trap with high capacity has been developed which can last for 50,000 miles and substantially reduce the numbers of desulfation events.
(3) $\mathrm{SO}_{\mathrm{x}}$ release due to desorption of the trapped sulfur species under rich condition is evaluated to be very small (in ppb level).

(4) Both surface adsorbed $\mathrm{SO}_{2}$ (prefer to form in low temperature) and metal sulfates (prefer to form in high temperature) are observed in $\mathrm{SO}_{x}$ absorber.

(5) Surface basicity and thermal stability determine the binding strength and trapping capacity of $\mathrm{SO}_{\mathrm{x}}$ absorber.

(6) Surface sulfation is a kinetically favored reaction with fairly low activation energy $\left(\Delta \mathrm{E}_{\mathrm{a}}\right)$ for both titania and Barium systems.

(7) The $\Delta E_{a}$ of de-sulfation for the titania-system is lower than the one for the Barium-system. It implies that the de-sulfation temperature in the titania-system is lower than the one in Bariumsystem (12 vs. 17 23 kcal/mole for $\Delta \mathrm{E}_{\mathrm{a}}$ ).
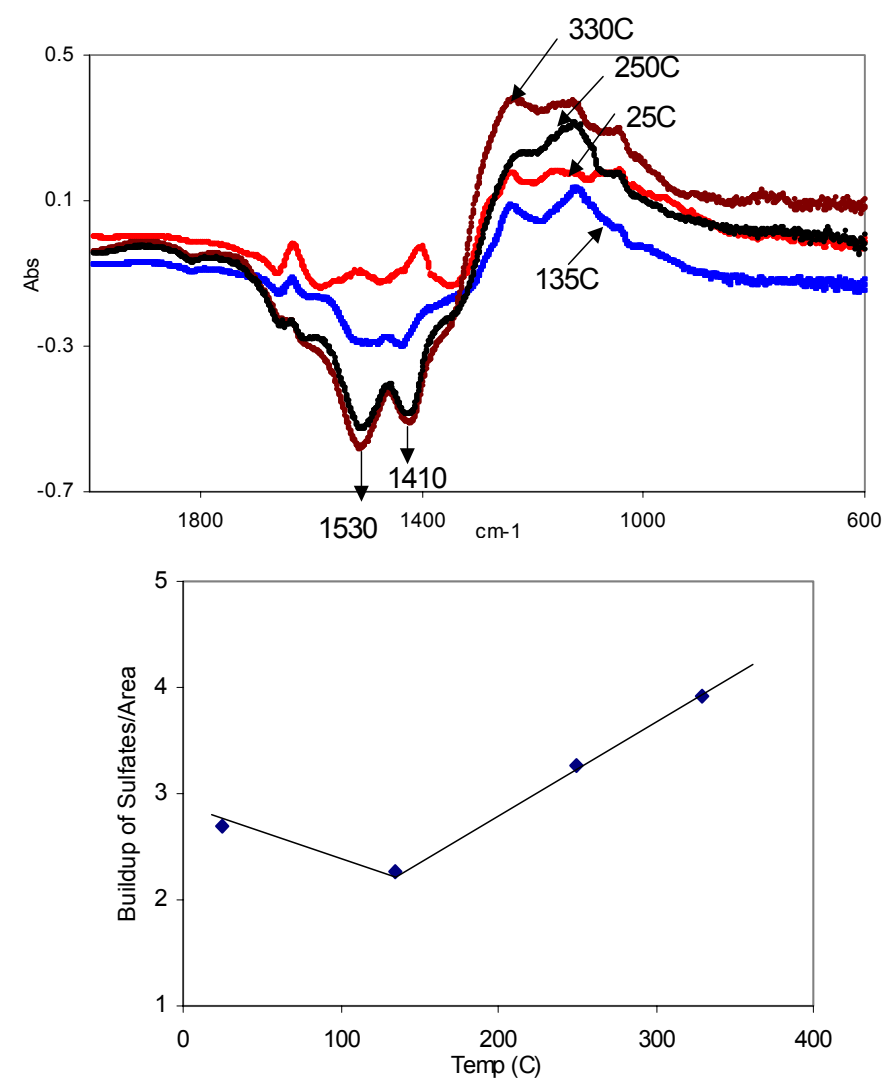

Figure 11: IR spectra and the V-shape response of commercial SOx trap material sulfated at various temperatures 


\section{REFERENCES}

1. Fang, H. L., Huang, S. C., Yu, R. C., Wan, C. Z. and Howden, K., "A Fundamental Consideration on NOx Adsorber Technology for DI Diesel Application", SAE2002-01-2889

2. Arakawa, K., Matsuda, S. and Kinoshita, H., "Progress in Sulfur Poisoning Resistance of Lean NOx Catalysts", SAE980930

3. Kobayashi, S., Nakajima, T. and Hori, M., "Effect of Fuel Sulfur and Aromatics on Diesel Exhaust Emissiomns", SAE918221, Kobayashi, T., Yamada, T. and Kayano, K., SAE970745

4. Miyoshi, N., Matsumoto, S., Tanaka, K., Harada, J., Takahashi, J., Yokota, N., Sugiura, M. and Kasahara, K., SAE950809

5. Bailey, O., Dou, D. and Denison, G. W., "Regeneration Strategies for NOx Adsorber Catalysts", SAE972845

6. Farrauto, R. J. and Mooney, J. J., "Effects of Sulfur on Performance of Catalytic Aftertreatment Devices", SAE920557

7. Guyon, M., Blejean, F., Bert, C. and LeFaou, P., "Impact of Sulfur on NOx Trap Catalyst Activity-Study of the Regeneration Conditions", SAE982607

8. Heck, R. M. and Farrauto, R. J., "Catalytic Air Pollution Control-Commercial Technology", van Nostrand Reinhold, New York, 1995

9. Heck, R. M., Catal. Today 53, 519 (1999)

10. W. H. Weber, "Raman Application in Catalysts for Exhaust-Gas Treatment" in "Raman Scattering in Materials Science", ed. by W. H. Weber and R. Merlin, Springer, Berlin (2000)

11. J. G. Grasselli and B. J. Bulkin, "Analytical Raman Spectroscopy" Wiley, New York (1997)

12. J. M. Stencel, "Raman Spectroscopy for Catalysis" Van Nostrand Reinhold (1990)

13. Coronado, J. M. and Anderson, J. A., J. Mol. Catal. A138 (1999)

14. Rodriguez, J. A., Jirsak, T. and Hrbek, J., J. Phys. Chem. B103, 1966 (1999)

15. Mitchell, M. B., Sheinker, V. K. and White, M. G., J. Phys. Chem. 100, 7550 (1996)

16. Waqif, M., Lavalley, J-C, Perathoner, S. and Centi, G., J. Phys. Chem. 95, 4051 (1991); Waqif, M., Bazin, P., Saur, O., Lavalley, J-C, Blanchard, G. and Touret, O., Appl. Catal. B11, 193 (1997); Waqif, M., Saad, A. M., Bensitel, M., Bachelier, J., Saur, O. and Lavalley, J-C, J. Chem. Soc. Faraday Trans., 88, 2931 (1992)

17. Busca, G., Ramis, G., Lorenzelli, V., Janin, A. and Lavalley, J-C, Spectrochim. Acta 43A, 489 (1987); Degen, I. A. and Newman, G. A., Spectrochim. Acta. 49A, 859 (1993)

18. Twu, J., Chuang, C. J., Chang, K. I., Yang, C. H. and Chen, H., Appl. Catal. B12, 309 (1997)
19. Thomas, J. M. and Thomas, W. J., "Principles and Practice of Heterogeneous Catalysis", $\mathrm{VCH}$, New York (1997)

20. H. Knozinger, Catal. Today 32, 71 (1996); I. E. Wachs, ibid. 27, 437 (1996)

21. W. H. Weber, K. C. Hass and J. R. McBride, Phys. Rev. B48, 178 (1993); G. W. Graham, W. H. Weber, C. R. Peters and R. Usmen, J. Catal. 130, 310 (1991)

22. F. H. Pollak, Ch. 6 in "Analytical Raman Spectroscopy" ed. by J. G. Grasselli and B. J. Bulkin, Wiley, New York (1997)

23. F. Tuinstra and J. L. Koenig, J. Chem. Phys. 53, 1126 (1970); Y. Wang, D. C. Alsmeyer and R. L. McCreery, Chem Matter. 2, 557 (1990); I. Pocsik, M. Hundhausen, M. Koos and L. Ley, J. Non-Crys. Solids 227B, 1083 (1998)

24. Wilde, J. D., Das, A. K., Heynderickx, G. H. and Marin, G. B., Ind. Eng. Chem. Res. 40, 119 (2001)

25. Ishizuka, T., Kabashima, T., Yamaguchi, T., Tanabe, K. and Hattori, H., Environ. Sci. Technol. 34, 2799 (2000); Tsuchiai, H., Ishizuka, T., Nakamura, H., Ueno, T. and Hattori, H., Ind. Eng. Chem. Res. 35, 851 (1996)

26. Matsumoto, S., Ikeda, Y., Suzuki, H., Ogai, M. and Miyoshi, N., Appl. Catal. B25, 115 (2000) 